\title{
Biological, electrical and echocardiographic indices versus cardiac magnetic resonance imaging in diagnosing left ventricular hypertrophy
}

\author{
Pierre-Yves Courand ${ }^{1,2,3,7}$, Nathalie Gaudebout ${ }^{4,7}$, Carine Mouly-Bertin ${ }^{1}$, Vivien Thomson ${ }^{5}$, \\ Jean-Pierre Fauvel ${ }^{2,3,6}$, Giampiero Bricca ${ }^{2,3}$ and Pierre Lantelme ${ }^{1,2,3,4}$
}

The aim of this study was to compare the diagnostic performance of N-terminal pro-brain natriuretic peptide (NT-proBNP), electrocardiographic (ECG) criteria and transthoracic echocardiography (TTE) versus cardiac magnetic resonance imaging in detecting left ventricular hypertrophy (LVH). The study included 42 hypertensive subjects with mean \pm s.d. age $48.1 \pm 12.3$ years, $57.1 \%$ men, $24-\mathrm{h}$ ambulatory blood pressure $144 / 89 \mathrm{~mm} \mathrm{Hg}$, left ventricular ejection fraction $>50 \%$, without symptoms of heart failure, and not taking any drugs that interfere with hormonal regulation. The accuracies of the methods in detecting LVH were compared at two diagnostic LVH cutoffs: low, $83 \mathrm{~g} \mathrm{~m}^{-2}$ in men and $67 \mathrm{~g} \mathrm{~m}^{-2}$ in women; and high, $96 \mathrm{~g} \mathrm{~m}^{-2}$ in men and $81 \mathrm{~g} \mathrm{~m}^{-2}$ in women. With the low and high LVH cutoffs, the areas under the receiver-operating characteristic curves and the optimal values for NT-proBNP were $0.761,0.849,200$ and $421 \mathrm{pg} \mathrm{ml}^{-1}$, respectively. An NT-proBNP level under $30 \mathrm{pg} \mathrm{ml}^{-1}$ ruled out LVH with $100 \%$ sensitivity. The optimal values and literature-based values of NT-proBNP allowed a correct classification of $73-81 \%$ of the subjects. In $80-90 \%$ of the cases, the diagnostic accuracy of NT-proBNP was close to that of ECG criteria but lower than that of TTE criteria. Interestingly, combining ECG criteria and NT-proBNP level improved the diagnostic performance to be at least comparable to that of TTE: the percentages of correctly classified subjects were 73-95\% vs. $67-86 \%$, respectively. Of note, the range considers both diagnostic LVH cutoffs. The simultaneous use of ECG criteria and NT-proBNP plasma levels seemed to be powerful enough to detect LVH in most hypertensive subjects.

Hypertension Research (2014) 37, 444-451; doi:10.1038/hr.2013.147; published online 17 October 2013

Keywords: cardiac magnetic resonance imaging; hypertension; left ventricular hypertrophy; NT-proBNP; transthoracic echocardiography

\begin{abstract}
INTRODUCTION
Left ventricular hypertrophy (LVH) has frequently been shown to be a powerful prognostic marker in hypertensive subjects. ${ }^{1-3}$ Among the numerous diagnostic tools that can be used to detect $\mathrm{LVH}$, the electrocardiographic (ECG) criteria are easily available and generally have a high specificity but a low sensitivity $(90 \%$ and $30 \%$, respectively). ${ }^{4}$ Transthoracic echocardiography (TTE) improves LVH detection to levels of sensitivity and specificity near $90 \%{ }^{5}$ but presents many limits, among which are an overestimation of the left ventricular mass (LVM), poor reproducibility, high cost and result unavailability in more than $10 \%$ of hypertensive subjects for technical reasons. ${ }^{6-8}$ Cardiac magnetic resonance imaging (CMR) is currently the gold standard for assessing LVM. This technique provides high-resolution images with excellent reproducibility. ${ }^{9-11}$
\end{abstract}

However, CMR is neither readily available nor cost-effective for LVM assessment in the routine evaluation of hypertensive subjects.

The use of N-terminal pro-brain natriuretic peptide (NT-proBNP) may be an alternative method to detect LVH in hypertensive subjects. Indeed, NT-proBNP plasma level is correlated with the TTE LVM index (LVMI). ${ }^{12,13}$ In addition, NT-proBNP has been compared with CMR in one study; ${ }^{14}$ its diagnostic value for LVH seemed sufficient, but the study included only 27 participants.

As the respective values of NT-proBNP, ECG and TTE in assessing LVH are currently unknown, the objective of the present study was to compare the diagnostic accuracies of these three methods with each other and to the accuracy of CMR, the reference method. The value of combining these markers was also tested.

${ }^{1}$ Cardiology Department, European Society of Hypertension Excellence Center, Hôpital de la Croix-Rousse, Hospices Civils de Lyon, Lyon, France; ${ }^{2}$ Génomique Fonctionnelle de I'Hypertension artérielle, Université Claude Bernard Lyon1, Villeurbanne, France; ${ }^{3}$ Hôpital Nord-Ouest, Villefranche sur Saône, France; ${ }^{4}$ Cardiology Department, Hôpital Nord Ouest, Villefranche-sur-Saône, France; ${ }^{5}$ Radiology Department, Hôpital de la Croix-Rousse, Hospices Civils de Lyon, Lyon, France and ${ }^{6}$ Nephrology and hypertension Department, Hôpital Edouard Herriot, Hospices Civils de Lyon, Lyon, France

Correspondence: Dr P-Y Courand, Cardiology Department, European Society of Hypertension Excellence Center, Hôpital de la Croix-Rousse, Hospices Civils de Lyon, 103 Grande Rue de la Croix-Rousse, F-69004 Lyon, France.

E-mail: pycourand@hotmail.com

7These authors contributed equally to this work.

Received 18 June 2013; revised 27 August 2013; accepted 9 September 2013; published online 17 October 2013 


\section{METHODS}

\section{Participants}

From June 2007 to September 2008, the study included 42 subjects referred to our center for the evaluation and treatment of hypertension. The exclusion criteria were the following: history or current symptoms of heart failure, left ventricular ejection fraction $<50 \%$ on echocardiography, aortic or mitral regurgitation of grade 3 or 4, atrial fibrillation, pulmonary fibrosis, cirrhosis, use of a pacemaker, presence of a metal implant, claustrophobia, pregnancy and age under 18 years.

The study was approved by the local ethics committee and by the Comite de Protection des Personnes de Lyon Sud-Est IV. All enrolled participants gave written informed consent.

\section{Protocol}

Before the hypertension work-up, any drugs likely to interfere with hormone regulation were withdrawn before admission (6 weeks for spironolactone and 2 weeks for diuretics, beta-blockers or renin-angiotensin system inhibitors) and were replaced with alpha-blockers, centrally acting drugs or calcium antagonists according to the current guidelines. ${ }^{15}$ Over 2 days of a hospital stay, all of the participants filled out a questionnaire (morphometric characteristics, cardiovascular risk factors, symptoms and so on) and underwent a physical examination and various biological tests (including plasma NT-proBNP), a 24-h recording of ambulatory blood pressure (BP), a 12-lead ECG and a CMR.

The body surface area (BSA) was calculated using the Dubois and Dubois formula; that is, $\mathrm{BSA}=0.20247 \times(\text { height })^{0.725} \times(\text { weight })^{0.725}$.

The electrical LVH criteria were defined as follows: a Sokolow-Lyon index (amplitude of leads SV1 + RV5 or RV6) $>3.5 \mathrm{mV}$, a Cornell voltage criterion ( $\mathrm{R}$ wave in aVL lead (RaVL) $+\mathrm{SV} 3$, with $8 \mathrm{~mm}$ added in women) $>2.8 \mathrm{mV}$ and a Cornell product $>2440 \mathrm{mmms}$ (Cornell voltage criterion $\times$ QRS duration). ${ }^{16-18}$ The amplitude of RaVL was also tested with a threshold of $6 \mathrm{~mm} \cdot{ }^{19,20}$

The plasma NT-proBNP concentration was assessed after one night in the supine position using an ELISA kit (Roche Diagnostics, Meylan, France; range 5-35000 $\mathrm{pg} \mathrm{ml}^{-1}$ ). Considering the previously published reference values for NT-proBNP in men and women in different age classes, ${ }^{21-23}$ all values under the 97.5th percentile for a given sex and age were considered to be in the normal range.

Two-dimensional images, M-mode and Doppler recordings were obtained from a Vivid Five ultrasound device (GE Vingmed Ultrasound, Horten, Norway). The thickness of the IVS (interventricular septum), that of the posterior wall, and the LVD (diameter of the left ventricle) were assessed according to the Penn convention. ${ }^{24}$ Each parameter was recorded over three consecutive heart beats, ignoring other data. The LV dimensions were determined from M-mode images and used to calculate LVM using the formula of Devereux: $\mathrm{LVM}=1.04\left[(\mathrm{IVS}+\mathrm{LVD}+\mathrm{PW})^{3}-\mathrm{LVD}^{3}\right]-13.6$. The LVMI was defined in two different ways: (i) indexation to the BSA (TTE $\mathrm{LVMI}^{\mathrm{BSA}}$ ) according to the European Society of CardiologyEuropean Society of Hypertension guidelines with the following LVH criteria: TTE LVMI BSA $>125 \mathrm{~g} \mathrm{~m}^{-2}$ in men and $>110 \mathrm{~g} \mathrm{~m}^{-2}$ in women; ${ }^{15}$ and (ii) indexation of height to the allometric power of 2.7 (TTE LVMI ${ }^{2.7}$ ) with the following LVH criterion: TTE LVMI ${ }^{2.7}>51 \mathrm{~g} \mathrm{~m}^{-2.7}$ in both sexes. ${ }^{25}$ Diastolic dysfunction was diagnosed when patients had an increased $\mathrm{E} / \mathrm{e}^{\prime}$ ratio $>15$ (average of three measurements of septal and lateral $\mathrm{e}^{\prime}$ ) as mentioned in the current European Society of Cardiology-European Society of Hypertension guidelines. ${ }^{26}$

CMR was performed using a 1.5T magnet (Magnetom Symphony Maestro Class, Siemens, Erlangen, Germany). Electrocardiogram-gated, breath-hold segmented, cine true fast imaging (True-FISP) was performed in long-axis views (four- and two-chamber views) and finally in short-axis views. On each short-axis slice, the endocardial and epicardial contours were manually traced at end diastole. LVM was derived using Simpson's method: after summation of the discs, the LVM was calculated by subtracting the endocardial volume from the epicardial volume at end diastole and multiplying the result by $1.05 \mathrm{~g} \mathrm{~cm}^{-3}$. Two previously described LVH cutoff values were considered: a low value of $83 \mathrm{~g} \mathrm{~m}^{-2}$ in men and $67 \mathrm{~g} \mathrm{~m}^{-2}$ in women ${ }^{27}$ and a high value at $96 \mathrm{~g} \mathrm{~m}^{-2}$ in men and $81 \mathrm{~g} \mathrm{~m}^{-2}$ in women. ${ }^{28}$

\section{Statistical analyses}

The qualitative variables are summarized as the mean \pm s.d., except those with skewed distributions, which are expressed as median values (boundaries of the interquartile ranges). Categorical variables were expressed as percentages. Student's paired or unpaired $t$-tests and nonparametric ANOVA (MannWhitney's $U$-test) were used to compare continuous variables between groups. The $\chi^{2}$-test was used to compare dichotomous variables.

The correlations between variables were assessed with a linear regression analysis (Pearson's coefficient of correlation ' $r$ '). A logarithmic transformation was applied to NT-proBNP, Sokolow-Lyon index, Cornell voltage criterion, Cornell product, RaVL lead, TTE LVMI ${ }^{2.7}$, TTE LVMI ${ }^{\mathrm{BSA}}$ and CMR LVMI values because of their skewed distributions. To test the independent association between NT-proBNP and CMR LVMI, a multiple linear regression analysis included the variables that had statistically significant correlations with NT-proBNP in univariate analyses.

To estimate the global accuracy of NT-proBNP, ECG indexes and TTE LVMI in diagnosing CMR LVH, an empirical receiver-operating characteristic (ROC) curve was built. To test the negative and positive predictive values, we used for NT-proBNP (i) our optimal values, (ii) values above the 97.5th percentile of the reference distribution according to age and $\operatorname{sex}^{21-23}$ and (iii) the NT-proBNP threshold proposed by Morillas et al. ${ }^{14}\left(35 \mathrm{pg} \mathrm{ml}^{-1}\right)$. For ECG criteria and TTE LVMI, we used values previously reported in the literature (see the Protocol paragraph above). The area under the ROC curve (AUC) was estimated using the Mann-Whitney test and was compared with 50\%. Various AUCs were compared using the $\chi^{2}$-test.

\section{RESULTS}

\section{Baseline characteristics}

There were 42 participants included in this study: 28 with essential hypertension, 10 with primary aldosteronism (6 adenomas and 4 adrenal hyperplasias) and 4 with secondary hyperaldosteronism (2 fibromuscular dysplasias and 2 atheromatous renal artery stenosis). The participants' baseline characteristics are summarized in Table 1. Using the low CMR LVMI cutoff values $\left(83 \mathrm{~g} \mathrm{~m}^{-2}\right.$ in men and $67 \mathrm{~g} \mathrm{~m}^{-2}$ in women), 16 subjects (12 men and 4 women) were classified as having LVH. These subjects had higher NT-proBNP levels, 24-h ambulatory BPs, Sokolow indexes, Cornell voltages, Cornell products, RaVL amplitudes and TTE LVMs than subjects classified without LVH. Using the high CMR LVMI cutoff values $\left(96 \mathrm{~g} \mathrm{~m}^{-2}\right.$ in men and $81 \mathrm{~g} \mathrm{~m}^{-2}$ in women), only nine men were classified as having LVH and showed the same differences $v s$. subjects classified without LVH regarding NT-proBNP levels and ECG indices (data not shown). NT-proBNP levels and age were not significantly different between women and men (123 (54-183) vs. 59 (30-158) $\mathrm{pg} \mathrm{ml}^{-1}, \quad P=0.286$ and $46.8 \pm 12.9$ vs. $49 \pm 12$ years, $P=0.525$, respectively)

A reliable measurement of LVM by TTE was obtained in 37 subjects (88\%). As expected, LVM was statistically overestimated by TTE compared with CMR (206 vs. $120 \mathrm{~g} ; P<0.001)$.

Using TTE LVMI $2.7>51 \mathrm{~g} \mathrm{~m}^{-2.7}$ as a cutoff, nearly half of the subjects were classified as having LVH (17 subjects, $49.6 \%$ ). The same number was found using TTE LVMI $^{\mathrm{BSA}}{ }^{\mathrm{B}}$; however, as expected, ECG criteria detected fewer LVH subjects: 9 (22.5\%) had a Sokolow-Lyon index $>3.5 \mathrm{mV}, 8(20 \%)$ had a Cornell voltage criterion $>2.8 \mathrm{mV}$, $10(25 \%)$ had a Cornell product $>2440 \mathrm{~mm} \mathrm{~ms}$ and $14(33 \%)$ had a $\mathrm{RaVL}>0.6 \mathrm{mV}$.

\section{Correlations between CMR LVMI and other parameters}

As shown in Table 2, considering the entire cohort, NT-proBNP, ECG criteria and TTE LVMI were all statistically correlated with CMR LVMI. Pearson's correlation coefficient between CMR LVMI and NT-proBNP was higher than that between CMR LVMI and the Sokolow-Lyon index. The best correlation with CMR LVMI was that 
Table 1 Baseline characteristics of the participant hypertensive subjects

\begin{tabular}{|c|c|c|c|c|}
\hline Characteristics & $\begin{array}{c}A l l \\
(\mathrm{~N}=42)\end{array}$ & $\begin{array}{l}\text { CMR LVH } \\
(\mathrm{N}=16)\end{array}$ & $\begin{array}{c}\text { No CMR LVH } \\
(\mathrm{N}=26)\end{array}$ & P-value \\
\hline \multicolumn{5}{|l|}{ Demographic characteristics } \\
\hline Ratio of women/men (\%) & $42.9 / 57.1$ & $25.0 / 75.0$ & $53.9 / 46.1$ & 0.067 \\
\hline Body surface area $\left(\mathrm{m}^{2}\right)$ & $1.85 \pm 0.20$ & $1.91 \pm 0.21$ & $1.81 \pm 0.19$ & 0.107 \\
\hline Height $(m)$ & $1.68 \pm 0.10$ & $1.70 \pm 0.09$ & $1.68 \pm 0.10$ & 0.487 \\
\hline \multicolumn{5}{|l|}{ 24-h ambulatory blood pressure } \\
\hline $\mathrm{SBP}(\mathrm{mm} \mathrm{Hg})$ & $144(126-163)$ & $176(147-201)$ & $131(125-144)$ & $<0.001$ \\
\hline $\mathrm{DBP}(\mathrm{mm} \mathrm{Hg})$ & 89 (79-96) & $103(92-122)$ & $81(77-89)$ & $<0.001$ \\
\hline Heart rate (b.p.m.) & $71.7 \pm 10.3$ & $72.3 \pm 9.8$ & $71.3 \pm 10.8$ & 0.778 \\
\hline \multicolumn{5}{|l|}{ Biochemical assays } \\
\hline NT-proBNP (pg ml-1) & $79(31-166)$ & $155(48-373)$ & $61(27-117)$ & 0.005 \\
\hline eGFR $(\mathrm{ml} \mathrm{min}-1)$ & $95.6 \pm 27.9$ & $89.9 \pm 18.8$ & $99.7 \pm 32.0$ & 0.273 \\
\hline LDL cholesterol $\left(\mathrm{g}^{-1}\right)$ & $1.24 \pm 0.33$ & $1.30 \pm 0.31$ & $1.20 \pm 0.33$ & 0.353 \\
\hline $\mathrm{HbAlc}(\%)$ & $5.3 \pm 0.4$ & $5.4 \pm 0.4$ & $5.3 \pm 0.4$ & 0.666 \\
\hline \multicolumn{5}{|l|}{$E C G$} \\
\hline Sokolow-Lyon index (mV) & $2.4(1.7-3.2)$ & $2.6(1.8-4.8)$ & $2.3(1.5-2.9)$ & 0.105 \\
\hline $\mathrm{R}$ wave in aVL lead (mV) & $0.5(0.2-0.9)$ & $1.0(0.6-1.5)$ & $0.3(0.2-0.6)$ & $<0.001$ \\
\hline Cornell voltage criterion (mV) & $1.8(1.4-2.4)$ & $2.8(2.0-3.1)$ & $1.6(1.4-2.0)$ & $<0.001$ \\
\hline Cornell product (mm ms) & $1627(1185-2543)$ & 2680 (1798-2872) & $1393(992-1706)$ & $<0.001$ \\
\hline \multicolumn{5}{|l|}{ Cardiac imaging } \\
\hline
\end{tabular}

Abbreviations: BMI, body mass index; b.p.m., beats per minute; CMR, cardiac magnetic resonance imaging; DBP, diastolic blood pressure; eGFR, estimated glomerular filtration rate; HbA1c, glycated hemoglobin; LDL, low-density lipoprotein; LVEF, left ventricular ejection fraction; NT-proBNP, N-terminal pro-brain natriuretic peptide; SBP, systolic blood pressure; TTE, transthoracic echocardiography.

Unless otherwise stated, the values are expressed as mean \pm s.d. or median (interquartile range).

LVH was defined with the following cutoff values: $83 \mathrm{~g} \mathrm{~m}^{-2}$ in men and $67 \mathrm{~g} \mathrm{~m}^{-2}$ in women.

Table 2 Correlations between LVMI CMR and various left ventricular mass indexes

\begin{tabular}{|c|c|c|c|c|c|c|c|c|c|c|}
\hline \multirow[b]{2}{*}{ Index } & \multicolumn{2}{|c|}{$\begin{array}{c}A l l \\
(\mathrm{~N}=42)\end{array}$} & \multicolumn{2}{|c|}{$\begin{array}{c}\text { Men } \\
(\mathrm{N}=24)\end{array}$} & \multicolumn{2}{|c|}{$\begin{array}{l}\text { Women } \\
(\mathrm{N}=18)\end{array}$} & \multicolumn{2}{|c|}{$\begin{array}{l}B M I<25 \\
(N=19)\end{array}$} & \multicolumn{2}{|c|}{$\begin{array}{l}B M I>25 \\
(N=23)\end{array}$} \\
\hline & r & P-value & $r$ & $\mathrm{P}$-value & $r$ & P-value & $r$ & P-value & $r$ & P-value \\
\hline NT-proBNP & 0.595 & $<0.001$ & 0.802 & $<0.001$ & 0.115 & 0.648 & 0.660 & 0.002 & 0.574 & 0.004 \\
\hline Sokolow-Lyon index & 0.462 & 0.002 & 0.515 & 0.010 & -0.018 & 0.942 & 0.363 & 0.126 & 0.539 & 0.008 \\
\hline Cornell voltage & 0.539 & $<0.001$ & 0.758 & $<0.001$ & 0.124 & 0.624 & 0.567 & 0.011 & 0.533 & 0.009 \\
\hline Cornell product & 0.606 & $<0.001$ & 0.730 & $<0.001$ & 0.344 & 0.162 & 0.660 & 0.002 & 0.585 & 0.003 \\
\hline $\mathrm{RaVL}$ & 0.571 & $<0.001$ & 0.643 & $<0.001$ & 0.306 & 0.217 & 0.610 & 0.006 & 0.554 & 0.006 \\
\hline TTE LVMI & 0.780 & $<0.001$ & 0.904 & $<0.001$ & 0.371 & 0.157 & 0.869 & $<0.001$ & 0.763 & $<0.001$ \\
\hline TTE LVMI 2.7 & 0.692 & $<0.001$ & 0.891 & $<0.001$ & 0.259 & 0.332 & 0.851 & $<0.001$ & 0.672 & $<0.001$ \\
\hline
\end{tabular}

Abbreviations: BMI, body mass index; CMR, cardiac magnetic resonance imaging; LVM, left ventricular mass; LVMI, left ventricular mass index; NT-proBNP, N-terminal pro-brain natriuretic peptide; $r$, Pearson's coefficient of correlation; RaVL, amplitude of $\mathrm{R}$ wave in aVL lead; TTE, transthoracic echocardiography.

A logarithmic transformation was applied to all variables. Correlations between variables were assessed with a linear regression analysis. 
of TTE LVMI. Correlations between NT-proBNP and CMR LVMI or TTE LVMI are illustrated in Figure 1. A subanalysis by sex showed higher correlation coefficients in men than that in women. Conversely, a subanalysis by body mass index class showed few differences between subjects with body mass index $<25 \mathrm{~kg} \mathrm{~m}^{-2}$ and subjects with body mass index $>25 \mathrm{~kg} \mathrm{~m}^{-2}$. To further confirm our data, we performed two sensitivity analyses: one after exclusion of patients with diastolic dysfunction and the other after exclusion of patients with CMR left ventricular ejection fraction $<60 \%$. NT-proBNP remained significantly correlated with CMR LVMI after exclusion of patients with diastolic dysfunction and left ventricular ejection fraction $<60 \%(N=38, r=0.532, P=0.001 ; N=30, r=0.495$, $P=0.005$, respectively).

Because of potential confounders, the relationship between NT-proBNP and CMR LVMI was also studied in a multivariate analysis that included the variables found significantly associated with NT-proBNP in univariate analyses, that is, 24-h ambulatory systolic
BP $(r=0.559 ; P<0.001)$ and active renin $(r=0.638 ; P<0.001)$. In this analysis too, NT-proBNP remained statistically and independently correlated with CMR LVMI (used here with log-transformed values, $r=0.324, P=0.042$ ).

\section{ROC curves}

The characteristics of the ROC curves are summarized in Table 3. With the low CMR LVMI cutoff values, the AUC for NT-proBNP was 0.761 (95\% confidence interval, 0.609-0.911; $P=0.005$, Figure 2a). An NT-proBNP level $<30 \mathrm{pg} \mathrm{ml}^{-1}$ ruled out LVH with $100 \%$ sensitivity, whereas a level above $380 \mathrm{pg} \mathrm{ml}^{-1}$ predicted LVH with $100 \%$ specificity. The best diagnostic value of NT-proBNP was obtained with $200 \mathrm{pg} \mathrm{ml}^{-1}$; this optimal level classified $76.2 \%$ of the subjects correctly with $43.5 \%$ sensitivity, $96.2 \%$ specificity, $87.5 \%$ positive predictive value and $69.4 \%$ negative predictive value. In comparison with other ECG criteria, the Sokolow-Lyon index had the worst diagnostic value. The largest AUC was that of TTE LVMI ${ }^{\mathrm{BSA}}$.
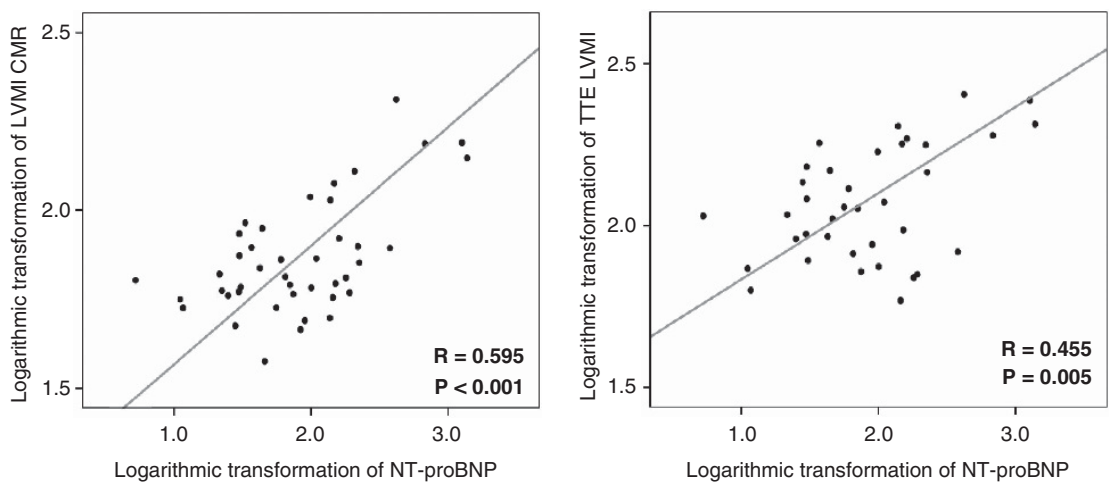

Figure 1 Pearson's correlations between NT-proBNP and LVMI. LVMI, left ventricular mass index; CMR, cardiac magnetic resonance; TTE, transthoracic echocardiography; CMR, cardiac magnetic resonance imaging; NT-proBNP, N-terminal pro-brain natriuretic peptide. A full color version of this figure is available at Hypertension Research online.

Table 3 Performance characteristics of various indices according to the two diagnostic CMR LVH cutoffs

\begin{tabular}{|c|c|c|c|c|c|}
\hline Index & $\operatorname{A\cup C}(95 \% \mathrm{Cl})$ & P-value & $\begin{array}{l}\text { Optimal } \\
\text { value }\end{array}$ & Specificity & Sensitivity \\
\hline \multicolumn{6}{|l|}{ Low LVH cutoffa } \\
\hline NT-proBNP & $0.760(0.609-0.911)$ & 0.005 & $200 \mathrm{pg} \mathrm{ml}^{-1}$ & 0.962 & 0.562 \\
\hline Sokolow-Lyon index & $0.650(0.467-0.834)$ & 0.105 & $3.9 \mathrm{mV}$ & 1 & 0.625 \\
\hline $\mathrm{RaVL}$ & $0.864(0.750-0.979)$ & $<0.001$ & $0.65 \mathrm{mV}$ & 0.885 & 0.750 \\
\hline Cornell voltage & $0.874(0.753-0.995)$ & $<0.001$ & $2.2 \mathrm{mV}$ & 0.962 & 0.688 \\
\hline Cornell product & $0.875(0.748-1.000)$ & $<0.001$ & $2099 \mathrm{~mm} \mathrm{~ms}$ & 1 & 0.750 \\
\hline TTE LVMI & $0.941(0.860-1.000)$ & $<0.001$ & $126 \mathrm{~g} \mathrm{~m}^{-2}$ & 0.913 & 0.929 \\
\hline TTE LVMI 2.7 & $0.923(0.848-1.000)$ & $<0.001$ & $60.4 \mathrm{~g} \mathrm{~m}^{-2.7}$ & 0.870 & 0.929 \\
\hline \multicolumn{6}{|l|}{ High $L V H$ cutoff $^{\mathrm{b}}$} \\
\hline NT-proBNP & $0.849(0.714-0.983)$ & $<0.001$ & $421 \mathrm{pg} \mathrm{ml}^{-1}$ & 1 & 0.444 \\
\hline Sokolow-Lyon index & $0.855(0.692-1.000)$ & $<0.001$ & $4.0 \mathrm{mV}$ & 1 & 0.667 \\
\hline RaVL & $0.897(0.792-1.000)$ & $<0.001$ & $1.0 \mathrm{mV}$ & 0.909 & 0.778 \\
\hline Cornell voltage & $0.919(0.800-1.000)$ & $<0.001$ & $2.7 \mathrm{mV}$ & 0.970 & 0.889 \\
\hline Cornell product & $0.960(0.878-1.000)$ & $<0.001$ & $2700 \mathrm{~mm} \mathrm{~ms}$ & 1 & 0.889 \\
\hline TTE ILVMI & $0.948(0.877-1.000)$ & $<0.001$ & $190 \mathrm{~g} \mathrm{~m}^{-2}$ & 1 & 0.625 \\
\hline TTE LVMI 2.7 & $0.931(0.846-1.000)$ & $<0.001$ & $76.1 \mathrm{~g} \mathrm{~m}^{-2.7}$ & 0.931 & 0.750 \\
\hline
\end{tabular}

Abbreviations: AUC, area under curve; $\mathrm{Cl}$, confidence interval; CMR, cardiac magnetic resonance imaging; LVH, left ventricular hypertrophy; LVM, left ventricular mass; LVMI, left ventricular mass index; RaVL, amplitude of $\mathrm{R}$ wave in aVL lead; TTE, transthoracic echocardiography.

a $83 \mathrm{~g} \mathrm{~m}^{-2}$ in men and $67 \mathrm{~g} \mathrm{~m}^{-2}$ in women.

b $96 \mathrm{~g} \mathrm{~m}^{-2}$ in men and $81 \mathrm{~g} \mathrm{~m}^{-2}$ in women. 
The AUC of NT-proBNP was not significantly different from the AUCs of the electrical LVH indexes $(P=0.292$ for Sokolow-Lyon index, $P=0.221$ for RaVL, $P=0.178$ for Cornell voltage and $P=0.203$ for Cornell product). The AUCs of TTE LVMI ${ }^{\mathrm{BSA}}$ and $\mathrm{LVMI}^{2.7}$ were significantly different from that of NT-proBNP ( $P=0.036$ and $P=0.032$, respectively).

With the high CMR LVMI cutoff values, the AUC for NT-proBNP increased up to 0.849 (95\% confidence interval, 0.714-0.983; $P<0.001$, Figure $2 \mathrm{~b}$ ) and the optimal level was $421 \mathrm{pg} \mathrm{ml}^{-1}$. This level correctly classified $88.1 \%$ of the subjects with $44.4 \%$ sensitivity, $100 \%$ specificity, $100 \%$ positive predictive value and an $86.8 \%$ negative predictive value. With the high CMR LVMI cutoff values, the AUCs and the optimal values were higher than that with the low CMR LVMI cutoff values for all ECG and TTE criteria (Table 3), and the AUC for NT-proBNP was not significantly different from the AUCs found for the electrical LVH indexes and TTE criteria ( $P=0.928$ for Sokolow-Lyon index, $P=0.475$ for RaVL, $P=0.250$ for Cornell voltage, $P=0.057$ for Cornell product, $P=0.055$ for $\mathrm{LVMI}^{\mathrm{BSA}}$ and $P=0.091$ for $\mathrm{LVMI}^{2.7}$ ).

After the exclusion of patients with diastolic dysfunction or CMR left ventricular ejection fraction $<60 \%$, the areas under the curves were slightly truncated both for NT-proBNP and ECG criteria, possibly because of the reduced number of patients remaining eligible for analysis (Supplementary Table S1; Supplementary Data).

\section{Predictive values of the diagnostic methods}

Table 4 displays the negative and positive predictive values as well as the rates of correctly classified subjects with each LVH criterion and according to each of the above-mentioned CMR LVMI cutoffs values. For each tool, we tested three NT-proBNP thresholds: the optimal value obtained with our ROC curves, Morillas' cutoff and the reference value obtained in a normal population; ${ }^{21-23}$ (Supplementary Table S2; Supplementary Data). The optimal value and the reference value (above the 97.5th percentile for age and sex) of NT-proBNP
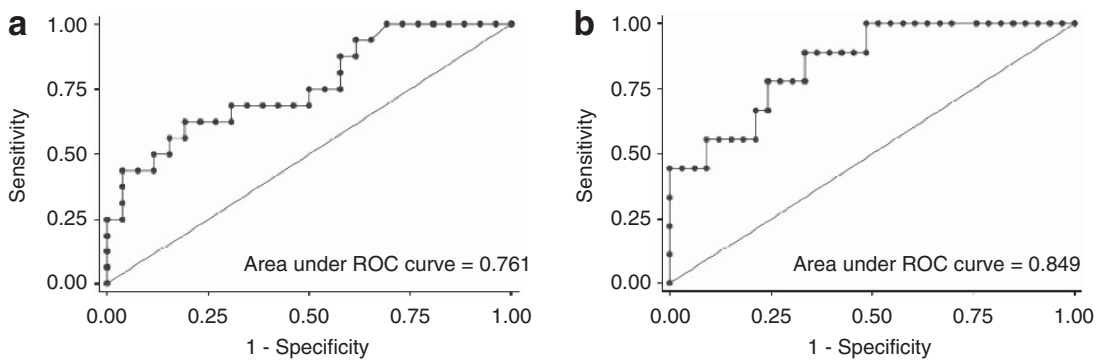

Figure 2 ROC curves for NT-proBNP as a diagnostic test for LVH as assessed by CMR. Panel a corresponds to the low LVH cutoff (83 $\mathrm{gm}^{-2}$ in men and $67 \mathrm{~g} \mathrm{~m}^{-2}$ in women) and panel b to the high LVH cutoff $\left(96 \mathrm{~g} \mathrm{~m}^{-2}\right.$ in men and $81 \mathrm{~g} \mathrm{~m}^{-2}$ in women). CMR, cardiac magnetic resonance imaging; NT-proBNP, N-terminal pro-brain natriuretic peptide; LVH, left ventricular hypertrophy. A full color version of this figure is available at Hypertension Research online.

Table 4 Predictive values of various LVH criteria according to the low and high CMR LVH cutoffs values

\begin{tabular}{|c|c|c|c|c|}
\hline LVH criteria & Positive predictive value & Negative predictive value & Rate of correctly classified patient & $A \cup C$ \\
\hline \multicolumn{5}{|l|}{ Low cutoff values ${ }^{a}$} \\
\hline NT-proBNP > $200 \mathrm{pg} \mathrm{ml}^{-1}$ & $87.5 \%(7 / 8)$ & $73.5 \%(25 / 34)$ & $76.2 \%(32 / 42)$ & 0.760 \\
\hline Reference values of NT-proBNP & $66.7 \%(10 / 15)$ & $77.7 \%(21 / 27)$ & $73.8 \%(31 / 42)$ & 0.760 \\
\hline Sokolow-Lyon index $>3.5 \mathrm{mV}$ & $66.7 \%(6 / 9)$ & $69.7 \%(23 / 33)$ & $69.0 \%(29 / 42)$ & 0.650 \\
\hline Cornell voltage $>2.8 \mathrm{mV}$ & $100 \%(8 / 8)$ & $76.5 \%(26 / 34)$ & $80.9 \%(34 / 42)$ & 0.874 \\
\hline TTE LVMI $>51 \mathrm{gm}^{-2.7}$ & $68.4 \%(13 / 19)$ & $94.4 \%(17 / 18)$ & $81.1 \%(30 / 42)$ & 0.944 \\
\hline TTE LVMI $>110 \mathrm{~g} \mathrm{~m}^{-2}$ in women, $>125 \mathrm{gm}^{-2}$ in men & $76.4 \%(13 / 17)$ & $95.0 \%(19 / 20)$ & $86.4 \%(32 / 42)$ & 0.921 \\
\hline \multicolumn{5}{|l|}{ High cutoff values ${ }^{\mathrm{b}}$} \\
\hline NT-proBNP $>421 \mathrm{pg} \mathrm{ml}^{-1}$ & $100 \%(4 / 4)$ & $86.8 \%(33 / 38)$ & $88.1 \%(37 / 42)$ & 0.849 \\
\hline NT-proBNP $>35 \mathrm{pg} \mathrm{ml}^{-1}$ & $26.7 \%(8 / 30)$ & $91.7 \%(11 / 12)$ & $45.2 \%(19 / 42)$ & 0.849 \\
\hline RaVL $>0.6 \mathrm{mV}$ & $53.3 \%(8 / 15)$ & $96.3 \%(26 / 27)$ & $80.9 \%(34 / 42)$ & 0.897 \\
\hline TTE LVMI $>51 \mathrm{gm}^{-2.7}$ & $36.8 \%(7 / 19)$ & $100 \%(18 / 18)$ & $67.6 \%(25 / 42)$ & 0.931 \\
\hline TTE LVMI $>110 \mathrm{~g} \mathrm{~m}^{-2}$ in women, $>125 \mathrm{~g} \mathrm{~m}^{-2}$ in men & $41.2 \%(7 / 17)$ & $100 \%(20 / 20)$ & $73.0 \%(27 / 42)$ & 0.948 \\
\hline
\end{tabular}

Abbreviations: AUC, area under curve; CMR, cardiac magnetic resonance imaging; LVH, left ventricular hypertrophy; LVM, left ventricular mass; LVMI, left ventricular mass index; RaVL, amplitude of $\mathrm{R}$ wave in aVL lead; TTE, transthoracic echocardiography.

a $>83 \mathrm{~g} \mathrm{~m}^{-2}$ in men and $>67 \mathrm{~g} \mathrm{~m}^{-2}$ in women.

b $>96 \mathrm{~g} \mathrm{~m}^{-2}$ in men and $>81 \mathrm{~g} \mathrm{~m}^{-2}$ in women. 

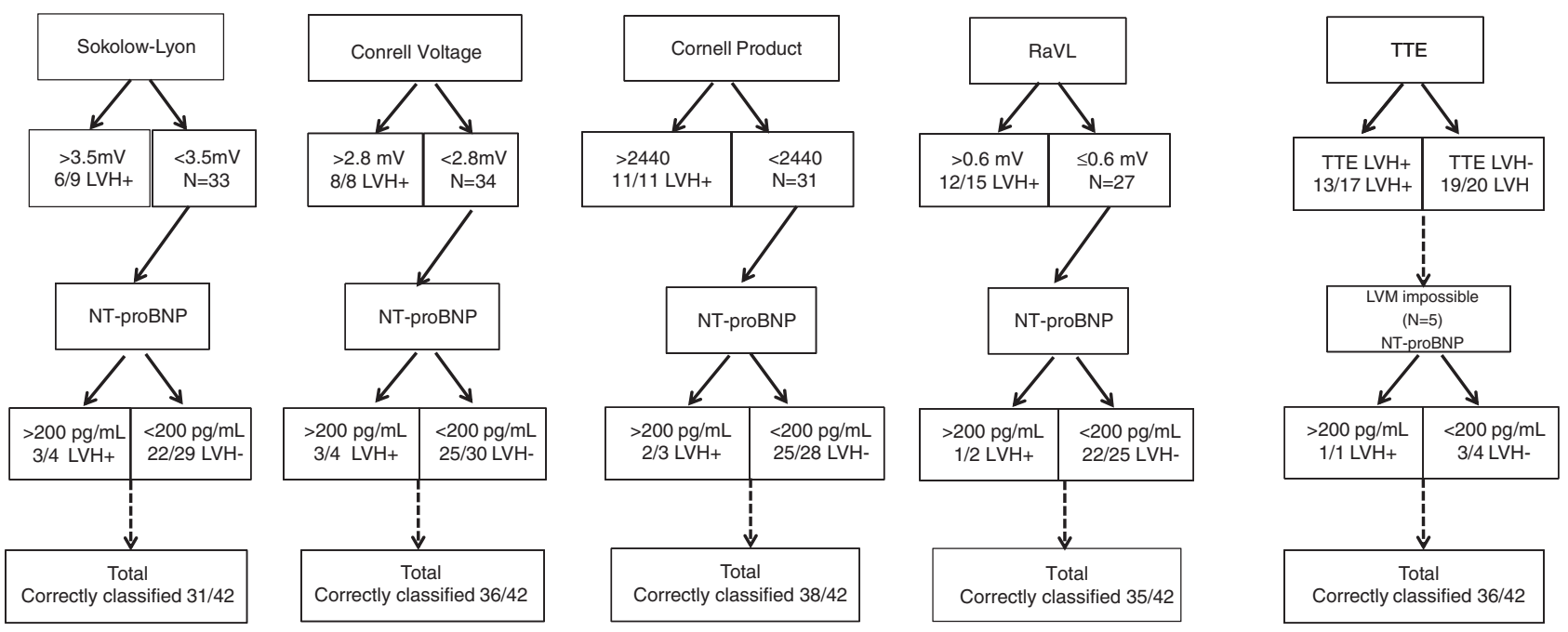

Figure 3 Imaging strategy (ECG or TTE first, and then NT-proBNP) to diagnose left ventricular hypertrophy with the low LVH cutoff of $83 \mathrm{gm}^{-2}$ in men and $67 \mathrm{~g} \mathrm{~m}^{-2}$ in women. ECG, electrocardiograph; LVH, left ventricular hypertrophy; LVM, left ventricular mass; NT-proBNP, N-terminal pro-brain natriuretic peptide; RaVL, amplitude of R wave in aVL lead; TTE, transthoracic echocardiography.

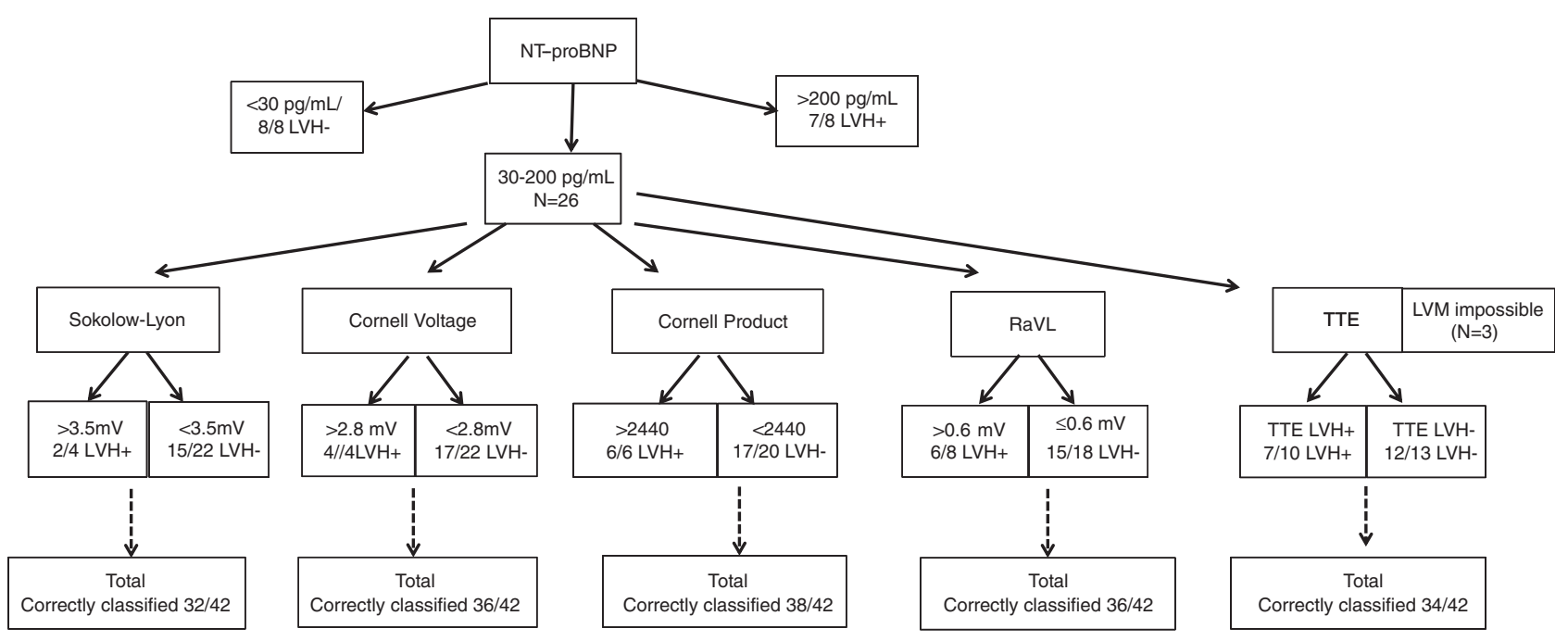

Figure 4 Biological strategy (NT-proBNP first, and then ECG or TTE) to diagnose left ventricular hypertrophy with the low LVH cutoff $83 \mathrm{gm}^{-2}$ in men and $67 \mathrm{~g} \mathrm{~m}^{-2}$ in women. ECG, electrocardiograph; LVH, left ventricular hypertrophy; LVM, left ventricular mass; NT-proBNP, N-terminal pro-brain natriuretic peptide; RaVL, amplitude of R wave in aVL lead; TTE, transthoracic echocardiography.

correctly classified $73 \%$ and $88 \%$ of the subjects, respectively. In comparison, Morillas' cutoff of $35 \mathrm{pg} \mathrm{ml}^{-1}$ correctly classified only $45.2 \%$ and $57.1 \%$ of the subjects according to the low and high CMR LVH cutoffs values, respectively. We also observed that the diagnostic accuracies of the Cornell voltage and the Cornell product were relatively close to that of TTE (80-90\%). The usual TTE LVMI ${ }^{\mathrm{BSA}}$ and $\mathrm{LVMI}^{2.7}$ cutoffs overestimated the prevalence of LVH regardless of the LVH cutoff values used for diagnosis.

We therefore tested two strategies to diagnose LVH with the low CMR LVMI cutoff: (i) ECG or TTE first and then NT-proBNP (imaging strategy, Figure 3); and (ii) NT-proBNP first and then ECG or TTE (biological strategy, Figure 4). The results obtained with the high cutoff are shown as Supplementary Data (Supplementary Figures S1 and S2). Whatever the strategy and the cutoff level, the rate of correctly classified subjects (except with the Sokolow-Lyon index) tended to be higher than that found using TTE criteria alone (83-95\% vs. $67-86 \%$, respectively).

\section{DISCUSSION}

This study confirmed the satisfactory performance of NT-proBNP against the gold standard of CMR in diagnosing LVH in hypertensive subjects. It demonstrated that the performance of the ECG + NTproBNP combination was not much different from that of TTE in diagnosing $\mathrm{LVH}$ in a population of hypertensive subjects without heart failure.

The present study found an association between NT-proBNP and CMR LVMI. Some studies have previously demonstrated a correlation between $\mathrm{BNP}^{29-32}$ or NT-proBNP ${ }^{12}$ and TTE LVMI, but others have not. $^{33,34}$ These contradictory results may be explained by the influence of the renin-angiotensin system on the plasma levels of natriuretic peptides. ${ }^{35}$ Indeed, renin-angiotensin inhibitors, diuretics and drugs that lower blood volume usually decrease natriuretic peptide concentrations. ${ }^{36}$ This was confirmed in a substudy of LIFE that showed an increase in NT-proBNP levels in the group treated with atenolol but a decrease in the group treated with losartan. ${ }^{37}$ 
At the time of the biological and imaging analyses in this study, none of the participants were receiving drugs that interfere with the reninangiotensin system. This is one of the major strengths of the study.

The results shown herein are in agreement with those obtained by Morillas et al. ${ }^{14}$ in a cohort of 27 hypertensive subjects; these authors have reported an AUC of 0.867 of NT-proBNP and a correlation of 0.589 with CMR LVMI. They mentioned a negative predictive value of $100 \%$ for the diagnosis of LVH at NT-proBNP levels $<35 \mathrm{pg} \mathrm{ml}^{-1}$. In this study, we found a similar performance with a threshold of $30 \mathrm{pg} \mathrm{ml}^{-1}$. However, the best diagnostic value of NT-proBNP was obtained with $200 \mathrm{pg} \mathrm{ml}^{-1}$, whereas Morillas et al. ${ }^{14}$ reported a much lower value of $35 \mathrm{pg} \mathrm{ml}^{-1}$ using a CMR cutoff of $83 \mathrm{~g} \mathrm{~m}^{-2}$ in men and $67 \mathrm{gm}^{-2}$ in women for LVH detection. In our cohort, the latter cutoff values were not able to predict LVH reliably $(<58 \%$ of correctly classified subjects, whatever the CMR LVMI cutoff). This difference may be explained by a lower proportion of women in the study by Morillas et al. ${ }^{14}$ compared with our study (15\% vs. $43 \%$, respectively). Indeed, at any given age, NT-proBNP normal values are slightly higher in women than that in men. ${ }^{21-23}$ Another potential explanation for the use of a lower threshold by Morillas et al. ${ }^{14}$ would be the assessment of subjects using diuretics or renin-angiotensin system inhibitors (unprovided data). Another choice for the NT-proBNP threshold is the literature reference values. ${ }^{21-23}$ Here, using these reference values led to $74-81 \%$ good classification.

The worst correlations observed in women were between CMR LVMI and each of ECG criteria, TTE LVMI and NT-proBNP. This can be explained by a narrow range of LVMI values and a small prevalence of LVH in women. Indeed, a previous study regarding TTE LVMI in a larger cohort demonstrated a better predictive value of NT-proBNP in detecting LVH in women than in men. ${ }^{12}$ In that study, the optimal value of NT-proBNP was $109 \mathrm{pg} \mathrm{ml}^{-1}$. This lower NT-proBNP threshold is in agreement with the overestimation usually found with TTE-estimated LVMs. ${ }^{6}$

As demonstrated here and in previous reports, the main limits in TTE assessment of LVM are poor reproducibility and lack of LVM measurement for technical reasons in $\sim 10 \%$ of hypertensive subjects who consult a general practitioner. ${ }^{19}$ In this regard, NT-proBNP and ECG criteria are likely to offer better interobserver and intraobserver reproducibility and are available to all patients. We have recently demonstrated that beyond the diagnosis of LVH, NT-proBNP has a powerful ability to predict mortality, ${ }^{38}$ and potentially allows for a more integrative approach to stratify the risk in hypertension and other conditions such as subclinical heart failure, afterload excess and arterial stiffness. ${ }^{35}$

$\mathrm{BP}$ is a major determinant of NT-proBNP level. ${ }^{12,35}$ This may be a limitation for its practical use because BP is highly variable. However, we performed a multivariate analysis including 24-h ambulatory BP monitoring as a potential confounder; despite this adjustment, NTproBNP was still associated with CMR LVMI. Moreover, we previously showed that the conditions of measurement, namely, ambulatory $v s$. standardized, and as a consequence, the related small BP changes, had very limited effects on NT-proBNP levels. ${ }^{38}$ Consequently, we believe that even if NT-proBNP is associated with $\mathrm{BP}$, the effect of small BP variations on its diagnostic value should be limited. In clinical practice, NT-proBNP could be the general practitioner's first approach to detect LVH in hypertensive subjects. All general practitioners are not equipped to perform ECG measurements; therefore, detecting LVH is not frequent. According to Spranger et al., ${ }^{39}$ only $11 \%$ of subjects with newly diagnosed hypertension were ordered to have an ECG. The Sokolow-Lyon index is likely the most popular, but we demonstrate here that its performance in detecting LVH is lower than that of NT-proBNP. In subjects with NT-proBNP values within the gray zone (30$200 \mathrm{pg} \mathrm{ml}^{-1}$ ), the interpretation of ECG by a trained practitioner (especially with Cornell Voltage, Cornell product and RaVL) allowed reaching rates $>85 \%$ of correct $\mathrm{LVH}$ classifications. The cardiologist may use NT-proBNP as a second step in subjects without electrical LVH signs. In the diagnosis of LVH, combining ECG and NT-proBNP offers a performance close to that of TTE. Finally, NT-proBNP may be used in subjects who already have had a TTE that could not precisely evaluate $\mathrm{LVH}$.

\section{Limits}

This study has the limits inherent to single-center, small-sample-size series: a low statistical power and a partial recruitment bias; one-third of the subjects were referred to our reference center for hypertension because of secondary hypertension. Another limit concerns NTproBNP; it is likely that it represents a criterion of LVH in subjects without heart or kidney failure. ${ }^{40}$ Unfortunately, we were not able to test the effect of renal failure on the diagnostic value of NT-proBNP as most of patients have preserved renal function. Nevertheless, in such a setting, false positive cases would correspond to high-risk conditions and lead to close control of BP.

\section{CONCLUSIONS}

This study confirms the good correlation between NT-proBNP and $\mathrm{LVH}$ as assessed by the current gold standard of CMR. Moreover, it shows that ECG criteria plus NT-proBNP offers a similar predictive value to that of TTE in detecting LVH. To optimize the detection of LVH with NT-proBNP, physicians should consider a threshold close to $200 \mathrm{pg} \mathrm{ml}^{-1}$ or refer to the normal values for sex and age. For costeffectiveness reasons, our results suggest performing TTE only in hypertensive subjects with murmur, cardiac symptoms or impaired renal function. Taken together, ECG criteria and NT-proBNP plasma levels seem to be powerful enough for risk stratification in subjects with hypertension.

\section{ACKNOWLEDGEMENTS}

We thank Jean Iwaz (Hospices Civils de Lyon, France) for a thorough editing of the manuscript.

1 Levy D, Anderson KM, Savage DD, Balkus SA, Kannel WB, Castelli WP. Risk of ventricular arrhythmias in left ventricular hypertrophy: the Framingham Heart Study. Am J Cardiol 1987; 60: 560-565.

2 McLenachan JM, Henderson E, Morris KI, Dargie HJ. Ventricular arrhythmias in patients with hypertensive left ventricular hypertrophy. N Engl J Med 1987; 317 787-792

3 Schillaci G, Verdecchia P, Borgioni C, Ciucci A, Zampi I, Battistelli M, Gattobigio R Sacchi N, Porcellati C. Association between persistent pressure overload and ventricular arrhythmias in essential hypertension. Hypertension 1996; 28: 284-289.

4 Alfakih K, Walters K, Jones T, Ridgway J, Hall AS, Sivananthan M. New gender specific partition values for ECG criteria of left ventricular hypertrophy recalibration against cardiac MRI. Hypertension 2004; 44: e13.

5 Korner PI, Jennings GL. Assessment of prevalence of left ventricular hypertrophy in hypertension. J Hypertens 1998; 16: 715-723.

6 Missouris CG, Forbat SM, Singer DR, Markandu ND, Underwood R, MacGregor GA Echocardiography overestimates left ventricular mass: a comparative study with magnetic resonance imaging in patients with hypertension. J Hypertens 1996; 14: 1005-1010.

7 Myerson SG, Montgomery HE, World MJ, Pennel DJ. Left ventricular mass: reliability of M-mode and 2-dimensional echocardiographic formulas. Hypertension 2002; 40: 673-678.

8 Gosse P, Cremer A, Vircoulon M, Coulon P, Jan E, Papaioannou G, Yeim S. Prognostic value of the extent of left ventricular hypertrophy and its evolution in the hypertensive patient. J Hypertens 2012; 30: 2403-2409. 
9 Katz J, Milliken MC, Stray-Gundersen J, Buja LM, Parkey RW, Mitchell JH, Peshock RM. Estimation of human myocardial mass with MR imaging. Radiology 1988; 169: 495-498.

10 Bottini PB, Carr AA, Prisant LM, Flickinger FW, Allison JD, Gottdiener JS. Magnetic resonance imaging compared to echocardiography to assess left ventricular mass in the hypertensive patients. Am J Hypertens 1995; 8: 221-228.

11 Myerson SG, Bellenger NG, Pennel DJ. Assessment of left ventricular mass by cardiovascular imaging resonance. Hypertension 2002; 39: 750-755.

12 Mouly-Bertin C, Bissery A, Milon H, Dzudie A, Rabilloud M, Bricca G, Vincent M, Lantelme P. N-terminal pro-brain natriuretic peptide-a promising biomarker for the diagnosis of left ventricular hypertrophy in hypertensive women. Arch Cardiovasc Dis 2008; 101: 307-315.

13 Andrade H, Morillas P, Castillo J, Roldán J, Mateo I, Agudo P, Quiles J, Bertomeu-Martínez V. Diagnostic accuracy of NT-proBNP compared with electrocardiography in detecting left ventricular hypertrophy of hypertensive origin. Rev Esp Cardiol 2011; 64: 939-941.

14 Morillas P, Castillo J, Nunez D, Guillen S, Maceira A, Rivera M, Bertomeu V. Usefulness of NT-proBNP level for diagnosing left ventricular hypertrophy in hypertensive patients. A cardiac magnetic resonance study. Rev Esp Cardiol 2008; 61: 972-975.

15 Mancia G, Fagard R, Narkiewicz K, Redón J, Zanchetti A, Böhm M, Christiaens T, Cifkova R, De Backer G, Dominiczak A, Galderisi M, Grobbee DE, Jaarsma T, Kirchhof P, Kjeldsen SE, Laurent S, Manolis AJ, Nilsson PM, Ruilope LM, Schmieder RE, Sirnes PA, Sleight P, Viigimaa M, Waeber B, Zannad F 2013ESH/ ESC guidelines for the management of arterial hypertension: the task force for the management of arterial hypertension of the European Society of Hypertension (ESH) and of the European Society of Cardiology (ESC). J Hypertens 2013; 31: 1281-1357.

16 Sokolow M, Lyon T. The ventricular complex in left ventricular hypertrophy using a new electrocardiographic left ventricular hypertrophy as obtained by unipolar precordial and limb leads. Am Heart J 1949; 37: 161-186.

17 Casale PN, Devereux RB, Alonso DR, Campo E, Kligfield P. Improved sex-specific criteria of left ventricular hypertrophy for clinical and computer interpretation of electrocardiograms: validation with autopsy findings. Circulation 1987; 75: 565-572.

18 Okin PM, Roman MJ, Devereux RB, Kligfield P. Electrocardiographic identification of increased left ventricular mass by simple voltage-duration products. J Am Coll Cardiol 1995; 25: 417-423.

19 Gosse P, Jan E, Coulon P, Cremer A, Papaioannou G, Yeim S. ECG detection of left ventricular hypertrophy: the simple, the better? J Hypertens 2012; 30: 990-996.

20 Verdecchia P, Angeli F, Cavallini C, Mazzotta G, Repaci S, Pede S, Borgioni C, Gentile $G$, Reboldi $G$. The voltage of $R$ wave in lead aVL improves risk stratification in hypertensive patients without ECG left ventricular hypertrophy. J Hypertens 2009; 27: 1697-1704.

21 Fradley MG, Larson MG, Cheng S, McCabe E, Coglianese E, Shah RV, Levy D, Vasan RS, Wang TJ. Reference limits for N-terminal-pro-B-type natriuretic peptide in healthy individuals (from the Framingham Heart Study). Am J Cardiol 2011; 108: 1341-1345.

22 Alehagen U, Goetze JP, Dahlström U. Reference intervals and decision limits for B-type natriuretic peptide (BNP) and its precursor (Nt-proBNP) in the elderly. Clin Chim Acta 2007; 382: 8-14.

23 Galasko GI, Lahiri A, Barnes SC, Collinson P, Senior R. What is the normal range for $\mathrm{N}$-terminal pro-brain natriuretic peptide? How well does this normal range screen for cardiovascular disease? Eur Heart J 2005; 26: 2269-2276.

24 Devereux RB. Detection of left ventricular hypertrophy by M-mode echocardiography. Anatomic validation, standardization, and comparison to other methods. Hypertension 1987; 9: 1119-1126.
25 De Simone G, Devereux RB, Daniels SR, Koren MJ, Meyer RA, Laragh JH. Effect of growth on variability of left ventricular mass: assessment of allometric signals in adults and children and their capacity to predict cardiovascular risk. J Am Coll Cardiol 1995; 25: 1056-1062.

26 McMurray JJ, Adamopoulos S, Anker SD, Auricchio A, Böhm M, Dickstein K, Falk V, Filippatos G, Fonseca C, Gomez-Sanchez MA, Jaarsma T, Kober L, Lip GY, Maggioni AP, Parkhomenko A, Pieske BM, Popescu BA, Ronnevik PK, Rutten FH, Schwitter J, Seferovic P, Stepinska J, Trindade PT, Voors AA, Zannad F, Zeiher A. ESC Committee for Practice Guidelines. ESC guidelines for the diagnosis and treatment of acute and chronic heart failure 2012: the task force for the Diagnosis and Treatment of Acute and Chronic Heart Failure 2012 of the European Society of Cardiology. Eur Heart J 2012; 33: 1787-1847.

27 Alfakih K, Reid S, Hall A, Sivananthan MU. The assessment of left ventricular hypertrophy in hypertension. J Hypertens 2006; 24: 1223-1230.

28 Sandstede J, Lipke C, Beer M, Hofmann S, Pabst T, Kenn W, Neubauer S, Hahn D. Age and gender-specific differences in left and right ventricular cardiac function and mass determined by cine magnetic resonance imaging. Eur Radiol 2000; 10: 438-442.

29 Kohno M, Horio T, Yokokawa K, Murakawa K, Yasunari K, Akioka K, Tahara A, Toda I, Takeuchi K, Kurihara N, Takeda T. Brain natriuretic peptide as a cardiac hormone in essential hypertension. Am J Med 1992; 92: 29-34.

30 Nishikimi T, Yoshihara F, Morimoto A, Ishikawa K, Ishimitsu T, Saito Y, Kangawa K, Matsuo H, Omae T, Matsuoka H. Relation between left ventricular geometry and natriuretic peptide levels in essential hypertension. Hypertension 1996; 28: 22-30.

31 Kohno M, Horio T, Yokokawa K, Yasunari K, Ikeda M, Minami M, Kurihara N, Takeda T. Brain natriuretic peptide as a marker for hypertensive left ventricular hypertrophy: changes during 1-year antihypertensive therapy with angiotensin-converting enzyme inhibitor. Am J Med 1995; 98: 257-265.

32 Almeida P, Azevedo A, Rodrigues R, Dias P, Frioes F, Vazquez B, Abreu-Lima C, Bettencourt P, Barros H. B-type natriuretic peptide and left ventricular hypertrophy in hypertensive patients. Rev Port Cardiol 2003; 22: 327-336.

33 Yasumoto $\mathrm{K}$, Takata $\mathrm{M}$, Ueno $\mathrm{H}$, Tomita S, Tomoda $\mathrm{F}$, Inoue $\mathrm{H}$. Relation of plasma brain and atrial natriuretic peptides to left ventricular geometric patterns in essential hypertension. Am J Hypertens 1999; 12: 921-924.

34 Nakamura M, Tanaka F, Ionezawa S, Satou K, Nagano M, Hiramori K. The limited value of plasma B-type natriuretic peptide for screening for left ventricular hypertrophy among hypertensive patients. Am J Hypertens 2003; 16: 1025-1029.

35 Bricca G, Lantelme P. Natriuretic peptides: ready for prime-time in hypertension. Arch Cardiovasc Dis 2011; 104: 403-409.

36 Throughton RW, Richards AM, Yandle TG, Frampton CM, Nicholls MG. The effects of medication on circulating levels of cardiac natriuretic peptides. Ann Med 2007; 39: 242-260.

37 Olsen MH, Wachtell K, Tuxen C, Fossum E, Bang LE, Hall C, Ibsen H, Rokkedal J, Devereux RB, Hildebrandt PR. Opposite effects of losartan and atenolol on natriuretic peptides in patients with hypertension and left ventricular hypertrophy: a LIFE substudy. J Hypertens 2005; 23: 1083-1090.

38 Paget V, Legedz L, Gaudebout N, Girerd N, Bricca G, Milon H, Vincent M, Lantelme P. $\mathrm{N}$-terminal pro-brain natriuretic peptide: a powerful predictor of mortality in hypertension. Hypertension 2011; 57: 702-709.

39 Spranger CB, Ries AJ, Berge CA, Radford NB, Victor RG. Identifying gaps between guidelines and clinical practice in the evaluation and treatment of patients with hypertension. Am J Med 2004; 117: 14-18.

40 Raymond I, Groenning BA, Hildebrandt PR, Nilson JC, Baumann M, Trawinski J, Pedersen F. The influence of age, sex and other variables on the plasma level of $\mathrm{N}$-terminal pro brain natriuretic peptide in a large sample of the general population. Heart 2003; 89: 745-775.

Supplementary Information accompanies the paper on Hypertension Research website (http://www.nature.com/hr) 